\title{
Socio-Cultural Factors of Food Insecurity in Sierra Leone
}

\author{
Michael Johnny $^{1 *} \quad$ Bashiru Mansaray ${ }^{2}$ \\ 1.Cabinet Secretariat, Office of the President, Tower Hill, Freetown, Sierra Leone \\ 2.Department of Agricultural Economics, Njala University, Private Mail Bag Freetown, Sierra Leone
}

\begin{abstract}
Food crop production in Sierra Leone is dominated by rice. It is cultivated by almost all small-scale farmers and consumed in all Sierra Leonean households irrespective of income levels. This underscores the importance attached to rice as a major staple crop. Sierra Leone is a rice deficit nation. Available statistics indicate that between 1970 and 2000, the country was self-sufficient in rice production only in 1975. Between 1979 and 2000, annual domestic paddy production fell from 504,000 to 200,000 Mt. During the same period, the volume of imported rice to fill domestic production shortfalls increased from 30\% to $60 \%$ of total rice consumption. The 1991-2002 civil war and associated insecurity throughout the rural areas resulted in a dramatic fall in production throughout the 1990s. Since the cessation of armed hostilities in 2002, the recovery of rice production in Sierra Leone has been impressive although self-sufficiency remains elusive. A peculiar feature of food availability in Sierra Leone (especially in rural communities) is its seasonality. Typically, there is widespread food scarcity in farming communities between the months of July and September each year. This seasonal food shortage is commonly referred to as the "hunger season." A plethora of explanations exist for the occurrence of the hunger season. The most frequently cited include insufficient supplies in store due to poor harvest; a lack of skills in storage; and crop loss due to inefficient processing/preservation techniques. This paper argues that apart from the production related explanations (such as insufficient supplies in store due to poor harvest; a lack of skills in storage; and crop loss due to inefficient processing/preservation techniques), several socio-cultural factors need to be considered in accounting for food insecurity in Sierra Leone.
\end{abstract}

Keywords: Socio-cultural, food insecurity, food production, Sierra Leone

DOI: $10.7176 / \mathrm{DCS} / 9-10-07$

Publication date:October $31^{\text {st }} 2019$

\section{Introduction}

In Sierra Leone possesses substantial mineral, agricultural, fishery and other natural resources but poverty is pervasive in this least-developed country and food insecurity is a major problem in both rural areas, where the majority of the population live, and in urban centres where a high percentage of the population are unemployed and chronically poor. The civil war, which ravaged the country between 1991 and 2002, disrupted virtually all productive activities, thereby entrenching poverty and exacerbating food security in the country generally. Significant improvements in economic growth have taken place since the end of the civil war but strong evidence still remains that food insecurity, hunger and malnutrition are significant on-going problems among a large percentage of households especially in rural areas. Food insecurity is, therefore, a major development challenge in Sierra Leone (Hart, 2006).

The 1996 World Food Summit defined food security as a state where "all people, at all times, have physical, social and economic access to sufficient, safe and nutritious foods to meet their dietary needs and food preferences to lead an active and healthy life"1. This widely accepted definition reinforces the multidimentional nature of food security and includes food access, availability, food use and stability. Achieving food security requires, therefore, that the following conditions are met: there must be sufficient food available to meet effective demand; everybody must have access to the food he or she needs; access and availability must be reliable and stable; and the food consumed must be effectively utilized /absorbed.

Availability of food supplies is currently insufficient in Sierra Leone. According to the 2008 Situational Assessment of the Food Crisis in Sierra Leone, which was jointly undertaken by the Ministry of Agriculture, Forestry and Food Security (MAFFS), FAO and WFP, imports of rice, the main staple, account for approximately one-third of national requirements. The main constraints to agricultural production and productivity include low availability of improved planting materials, the general unavailability of agro-chemicals (fertilizer, pesticides, etc), the use of rudimentary farming tools, high post-harvest losses (due to inefficient processing equipment and inadequate storage) and the paucity of market outlets resulting from poor road infrastructure.

Access to food through purchase is constrained by a combination of factors including widespread income poverty and low purchasing power, physical isolation, and inadequate market and transportation infrastructure. Estimates vary widely but it is strongly believed that over $70 \%$ of the population of Sierra Leone, comprising subsistence farmers in rural communities and the urban poor typically eat only one meal per day. The recent phenomenal increase in the prices of food stuffs has resulted in an increasing number of urban poor going without

\footnotetext{
${ }^{1}$ See Final Report - Part 1 of FAO World Food Summit, 1996. www.fao.org $>$ WFS
} 
food for a number of days at a time.

Reliability and stability of food supplies year-round are hampered by the physical remoteness and isolation of many of the poorest communities, particularly during the so-called "hunger season" which occurs between July and September each year and as a result of shocks. As rural access roads are underdeveloped and other road networks are in a state of disrepair, it is difficult to evacuate the food crop harvests from surplus producing areas to deficit ones and to stimulate integration of the domestic market. The inadequacy of agricultural processing and storage facilities further compounds the problem. In the face of shocks, the absence of an effective food safety net system exacerbates pre-existing food vulnerabilities.

Utilization/absorption of food is affected not only by lack of access to food, particularly to micro-nutrient rich foods, but also to safe drinking water, sanitation facilities and basic health services, as well as by insufficient knowledge about balanced diets, good nutrition and hygiene. It is estimated that less than $25 \%$ of the population has access to safe drinking water; that less than 505 are knowledgeable about good nutrition; and that only $11 \%$ have access to adequate sanitation facilities. Malaria, diarrhea and cholera are the most common public health problems arising from poor access to portable water and sanitation facilities. These indicators are of course, closely correlated with poverty. The 1991-2002 civil war worsened the situation as essential, albeit inadequate, health and social infrastructure and services were vandalized or destroyed, particularly in the rural areas.

Food insecurity, on the other hand, is defined by the World Health Organization as " limited or uncertain availability of nutritionally adequate and safe foods or limited or uncertain ability to acquire acceptable foods in socially acceptable ways."

Underlying the above is the principle that food security is a fundamental human right which all governments must respect and address. Food insecurity can lead to social and political instability in the form of food riots, increased crime (such as stealing and drug peddling) as young people seek to satisfy basic needs and political protests. Food insecurity has also been linked the spread of HIV/AIDS, which negatively impacts the well-being and rights of especially girls and women. Owing largely to poverty, many urban youth and women have adopted prostitution as a coping mechanism, thereby exposing themselves to the risk of infection by STDs. It is, thus, imperative that awareness be raised about the crucial need to address national food security through enhancing the productive capacities of local communities.

This paper argues that apart from the production related explanations, several socio-cultural factors need to be considered in accounting for and addressing food insecurity in Sierra Leone. As a complement to the conventional measures to promote food security, therefore, the effect of these socio-cultural issues on household food security need to be taken into account and appropriate extension messages for farmers developed and incorporated in the training programmes of agricultural extension personnel, if Government's priority goal of national food security is to be realized.

\section{Food production in Sierra Leone}

Food crop production in Sierra Leone is dominated by rice, the main staple. It is cultivated by almost all smallscale farmers and consumed in all Sierra Leonean households irrespective of income levels ${ }^{2}$. The per capita consumption of rice is estimated at $104 \mathrm{~kg}$ per annum ${ }^{3}$. In terms of contribution of rice to total calorie intake, the country ranks highest in sub-Saharan Africa. This indicates the high dependence of Sierra Leoneans on rice to meet their daily energy requirements and underscores the importance attached to rice as a major staple crop.

Even before the civil war, Sierra Leone was a rice deficit nation. Available statistics indicate that between 1970 and 2000, the country was self-sufficient in rice production only in 1975. Between the periods 1979-1981 and 1999-2000, domestic paddy production fell from 504,000 to 200,000 $\mathrm{Mt}^{4}$. During the same period, the volume of imported rice to fill domestic production shortfalls increased from $30 \%$ to $60 \%$ of total rice consumption. The civil war and associated insecurity throughout the rural areas resulted in a dramatic fall in production throughout the 1990s. Since the cessation of armed hostilities in 2002, the recovery of rice production in Sierra Leone has been impressive although self-sufficiency remains elusive ${ }^{5}$.

Besides rice, farmers in Sierra Leone also cultivate a wide variety of other food crops including cassava, sweet potatoes, yams, banana, plantain, a host of local vegetables, etc. Cassava is the second most important food crop: both the tuber and leaves are consumed. The pattern of food consumption in Sierra Leone has remained virtually unchanged over the decades with cereals, mostly rice, accounting for (on average) $56 \%$; roots and tubers,

\footnotetext{
${ }^{1} \mathrm{WHO}$, The state of food security and nutrition in the world (2018): https://www.who.int>nutrition

${ }^{2}$ GoSL: Sierra Leone Poverty Reduction Strategy Paper, 2005.

${ }^{3}$ GoSL: Agricultural Sector Review, 2003.

${ }^{4}$ GoSL, Agricultural Sector Review, 2003.

${ }^{5}$ A crop survey that was jointly conducted by FAO, WFP and MAFFS in 2002 estimated that total paddy production in $2001 / 2002$ cropping season was $420,000 \mathrm{MT}$, which was more than double the production in the previous cropping season, and represented an $84 \%$ recovery compared to production estimates for the three years (1988-1990) that immediately preceded the civil war. However, domestic rice production in 2002 was only $49 \%$ of the total consumption needs of the population.
} 
$6 \%$; pulses, $4 \%$; animal products, $5 \%$; and others, $29 \%$ of the total dietary energy supplies ${ }^{1}$.

\section{Seasonality of food availability}

A peculiar feature of food availability in Sierra Leone (especially in rural communities) is its seasonality. Typically, there is widespread food scarcity in farming communities between the months of July and September each year. This seasonal food shortage is commonly referred to as the "hunger season"(Richards, 1986). ${ }^{2}$ The most frequently cited include insufficient supplies in store due to poor harvest; a lack of skills in storage; and crop loss due to inefficient processing/preservation techniques. In consequence, all programmes of the MAFFS and its development partners are geared towards increasing farm productivity and improving post-harvest practices.

\subsection{Causes of the "Hunger Season"}

A plethora of explanations exist for the occurrence of the hunger season. The most frequently cited include insufficient supplies in store due to poor harvest; a lack of skills in storage; and crop loss due to inefficient processing/preservation techniques. ${ }^{3} \mathrm{FAO}$ contends that drought and conflict are major factors that have exacerbated the problem of food production, distribution and access. FAO further asserts that high rates of population growth and poverty have played a part within an already difficult environment of fragile ecosystems. ${ }^{4}$ This paper is based on research carried out in the Moyamba area, Southern Sierra Leone, in 1978/79 and followup in various communities in the country in 2002 and 2016. The key research methods included; i) participant observation, in which asking questions and listening are blended together as the researcher takes part in the life and socio-economic activities of the respondents; ii) focus group discussions with local stakeholders to elicit information on various aspects of community life; and iii) direct measurements to determine such variables as household size, farm size, rice yield per hectare and household food consumption. Based on the findings, the authors argue that no single explanation adequately accounts for the hunger season phenomenon but rather that it is owed to a combination of the following factors:

\subsubsection{Low levels of production}

The main staple, rice, is cultivated in five distinct ecologies - uplands, inland valley swamps, riverain grasslands, bolilands, and mangrove swamps. Although significant yield variations exist between these ecologies, all current yields are low when compared with those obtainable with improved cultural practices. Reasons for the low yields include poor planting materials, rudimentary farming implements, virtual non-utilization of agro-chemicals, outdated cultural practices, and dependence on labour-intensive technologies against the backdrop of high and accelerating migration of farm labour force to urban and other places of economic opportunity (Johnny, 1979; Johnny, Karimu, \& Richards, 1981).

\subsubsection{High post-harvest losses}

Post-harvest losses are due mainly to inefficient processing, preservation and storage. Estimates of crop loss due to these factors vary, but are generally excessive. Crop loss can be as high as $30 \%$ for cereals (like rice, maize and sorghum) and $70 \%$ for fruits and vegetables. Tubers rank second only to rice as local staple crops. Substantial progress has been made in processing cassava - the most important tuber - into various products. However, efforts to process tubers, generally, thereby extending their shelf life, are at an incipient stage and lack much to be desired. With the notable exceptions of yam and coco-yam, which can survive fairly lengthy periods in sub-optimal conditions, many tubers (like sweet potato) deteriorate rapidly after harvest. As much as $50 \%$ of the potato harvest can be lost in relatively short periods while awaiting buyers. For this reason, many tubers have to be sold off immediately after harvest (often at very low prices) or consumed domestically in unnecessarily large quantities. 3.1.3 Labour availability at household level

Food production in Sierra Leone is labour-intensive. There is, therefore, a high correlation between labour availability at household level and the level of food security. Available labour dictates the size of the household farm and determines participation or otherwise in cash cropping. Smaller than average households tend to produce only food crops, while larger households venture into cash cropping. The implication is that small households often have to sell some of their meager food to meet urgent cash needs, thereby further undermining their food security. Labour availability also facilitates participation in non-agricultural productive activities (such as diamond and gold mining) which can significantly improve a household's access to food.

3.1.4 Dietary habits

A peculiarity of the dietary habits of the vast majority of Sierra Leoneans (especially those in rural communities) is the over-dependence on rice. Apart from coastal fishing communities in the Bonthe, Pujehun and Moyamba districts in the Southern Province, where cassava (with fish) is the predominant staple, the word "food" is

\footnotetext{
${ }^{1}$ Report of the Vulnerability Analysis and Mapping exercise jointly carried out by the Government of Sierra Leone in collaboration with WFP, UNDP, UNICEF, WHO and FAO, March 2006 (Hart, 2006)

2 See (Richards, 1986) and Johnny, Michael (2002). The Hunger Season in Sierra Leone, FAO Consultancy Report, Freetown.

3 GoSL, Agricultural Sector Review, 2003, 2004

4 FAO, Underlying causes of food insecurity, www.fao.org
} 
synonymous with rice. Apart from these coastal communities, therefore, the vast majority of rural people narrate experiences during the "hunger season" when they "go without food for several days at a time". Further investigation usually reveals, however, that during these periods, they consume cassava, yam, wild yam, sweet potato, etc. given the dietary habits in Sierra Leone; a clear distinction needs to be made between "food insecurity" and "rice insecurity".

There appears to be a seasonal rhythm to the pattern of rice consumption. The average amount of rice consumed by an average household size of 6 persons can be as high as 12 cups in January (just after the main harvest). This is reduced gradually to 4 cups or less between July and September (the so-called "hunger season") but increases gradually after that period until it peaks at 12 cups in December. During the hunger season, there is a tendency for more tubers to be consumed.

3.1.5 Poor management of available food:

An emerging viewpoint is that a major cause of seasonal food shortage in rural areas is the rather extravagant use of available food for various socio-cultural purposes. In other words, it is contended that the hunger season is, to a large extent, a culturally induced phenomenon, rather than evidence of the inability of traditional farming systems to produce enough food for local communities. A case study from the Moyamba area (Southern Province) in 1979 (Johnny, 1979) and follow-up by the same author in 2016 which measured annual rice production from upland farming and consumption by households would appear to substantiate this contention.

Table 1. Annual household production and consumption of upland rice in Moyamba Area.

\begin{tabular}{|l|l|l|}
\hline Parameter & Previous records (Johnny, 1979) & Fieldwork by authors 2016 \\
\hline Average household size & 6.8 persons & 6.2 persons \\
\hline Average farm size & 1.8 hectares & 1.5 hectares \\
\hline Yield per hectare & $1,064 \mathrm{~kg}$ & $1,112 \mathrm{~kg}$ \\
\hline Yield: Husk rice & $1,915 \mathrm{~kg}$ & $1,668 \mathrm{~kg}$ \\
Clean rice & $1,186 \mathrm{~kg}$ & $1,032 \mathrm{~kg}$ \\
\hline Clean rice consumption: & & \\
$\bullet \quad$ Per day & $2.2 \mathrm{~kg}$ & $2.0 \mathrm{~kg}$ \\
$\bullet \quad$ Per year & $803 \mathrm{~kg}$ & $730 \mathrm{~kg}$ \\
\hline
\end{tabular}

Sources: Authors' computation, fieldwork 2016

These are average figures which mask the circumstances of individual households but it is discernible from both studies that, on average, farmers do produce enough rice for household consumption.

3.1.6 The lavish use of food for festivities

The period immediately after harvest (October-January) coincides with several religious and secret societal festivities. Religious celebrations include Ramadan and Christmas, while the latter include the poro and wunde initiation ceremonies for young men and the bundo initiation for girls. During these festivities, inordinately high quantities of rice are consumed. Farmers estimate that for initiation ceremonies, approximately 1 bushel (27kg) of clean rice is contributed per initiate per fortnight. Typically, these ceremonies last for longer than one month though for various reasons, especially consideration for schooling, the trend is to reduce their duration.

3.1.7 Excessive food consumption at harvest time

During the period of rice harvest, most rural households consume significantly more food per day than usual. Typically, they do not measure the quantity prepared and tend to eat as much as they can. Farmers explain that this behavior is intended to make up for weight loss associated with the hunger season.

3.1.8 Loan repayment

During the farming calendar, many farmers obtain loans from village merchants and moneylenders for various needs. Interest rates on such loans are often very high and repayment is typically in farm produce, at harvest time when, due to glut, prices are at their lowest. In bad tears, loan repayment can claim up to half of some farmers' harvests.

\subsubsection{Poor road network:}

Many rural access roads are undeveloped and/or in disrepair. During the rainy season, when food stocks are lowest in some rural communities, some of these roads become impassable to vehicular traffic. It thus becomes difficult to evacuate food from surplus producing areas to food deficit ones.

\subsection{Populations that Experience "Seasonal Hunger"}

Seasonal hunger is characteristically a rural phenomenon. Food insecurity is also severe among the urban poor but here the problem is perennial. Seasonal food shortages are also not experienced in areas of intensive (nonagricultural) economic activities - mines, marketing centres, etc. In such localities, year-round access to financial resources prevents the occurrence of food shortages (Johnny, 1981).

In rural areas, the groups at greatest risk of seasonal hunger include those that live in smaller than averagesized households (especially where the individuals concerned are old, handicapped or chronically sick). Households with female heads - women who lost their husbands during the 1991-2002 civil war or during the 
Ebola pandemic, which ravaged the country from May 2014 to November 2015 - must now be added to the category of persons most likely to experience periodic food shortages. Smaller than average household size is an important factor in continued vulnerability to hunger because such households often lack the labour required to produce enough food and because lack of in-house labour restricts the scope for recovery from random shocks such as illness or adverse weather conditions (Richards, 1986).

\subsection{Coping Strategies}

Rural people have, over the years, devised resourceful strategies of adaptation to the reality of seasonal hunger. The most common are outlined as follows:

3.3.1 Agricultural strategies:

It is often observed that upland rice farming is a risk aversion strategy. The wide range of intercrops ensures first, that even in the event of main crop failure, some food is available for household subsistence and secondly, different crops ripen and are harvested at different times thereby ensuring the availability of food even during lean periods. In addition to upland intercrops, household members do, when labour permits, cultivate separate plots of groundnuts, cassava, sweet potatoes, etc. some of these crops are consumed by the household while some are sold to meet cash needs.

3.3.2 Non-agricultural strategies: ${ }^{1}$

Hunting and gathering: Forests and farm bush (in the Eastern and Southern Provinces) and grasslands (especially in the Northern Province) provide a wide range of foodstuffs and other useful products to those with the knowledge, interest and skill to collect them. In the south and east of the country, the wild (or bush) yam (Dioscorea minutiflora), is one of the most important of these, in terms of hunger season survival. It is so common in some localities that it sometimes serves as short-term staple where the rice has been depleted.

In all three provinces, wild oil palm is tapped for palm wine which serves as food for work in many communities during periods of food shortage. Wild oil palm is also harvested for palm oil - the nation's favorite cooking oil - which is either consumed by the household or sold. Hunting -either using guns or in pest drives and inland fishing by women are the main sources of animal protein during the dry season in all three provinces.

Change of eating habits: During the hunger season, there is a tendency for fewer (and more meager) meals to be prepared than at harvest time. The number of meals per day is usually reduced from three to one. During this period, meals also become more diversified as people tend to eat whatever is available. Cassava, bush yams, etc. become the short-term staples of many households.

Borrowing: As a coping strategy, borrowing appears to be a last resort in most communities. Not surprisingly, the most regular borrowers are the most vulnerable population, while lenders tend to be village or visiting traders, who lend food, various commodities and, sometimes, money. The rates of interest charged appear too high but there is a curious lack of hostility to lenders. Lenders are considered as helpful probably due to the fact that without their lending activities many rural households would find it difficult to survive.

Pledging: Owners of houses or tree crop plantations sometimes secure loans against security of these assets. As a strategy for coping with seasonal hunger, pledging is relevant only to comparatively well-to-do people. The most vulnerable - the old, chronically sick and handicapped - often do not have assets to pledge.

Migration of youth to areas of economic opportunity: Youth often migrate to towns and mines in search of economic opportunities. Their absence from their villages reduces pressure on available food, while remittances they make assist their families through the lean period.

Selling of household labour: It is not unusual for farmers to attempt to solve their food shortage problem by working for other farmers for cash. Men may join a ploughing group or women, a weeding group, with this objective in mind. Unfortunately, the groups that are worst affected by seasonal hunger are the least likely to employ this solution, as they often do not have enough labour for themselves.

\section{Effects of Seasonal Food Insecurity on Affected Communities}

Loans are contracted at high rates of interest and repayments are typically in farm produce at harvest time when prices are at their lowest. This practice undermines the future food security of affected households as they are trapped in the vicious cycle of borrowing and repaying each year.

Many farmers who pledge their property to meet collateral requirements of loans often lose such property due to inability to repay.

Youth who migrate to areas of economic opportunity to address the seasonal food needs of their families sometimes remain permanently in those communities. This negatively impacts the food production capacity of affected households as farming is labour intensive.

Seasonal hunger results in under- and mal-nutrition which, in turn, lead to ill health. The significance of health for farming activities is obvious: sickness adversely affects the ability of farmers to be productive. Small

\footnotetext{
${ }^{1}$ This sub-section is derived from fieldwork by (Richards, 1986) and the author at different locations in Moyamba district(Johnny et al., 1981).
} 
households are particularly vulnerable in this regard and farming can be abandoned in a particular year because the one or two adult males of the household fall sick during crucial periods in the farming calendar.

\section{Conclusions}

Conventional wisdom, which ascribes the food shortage problem only to 'agricultural' factors - low levels of production, poor processing, inefficient preservation and storage practices - continues to guide Sierra Leone's food security policy. Thus, all programmes of the Ministry of Agriculture, Forestry and Food Security (MAFFS) are geared towards increasing farm productivity and improving post-harvest practices. In conformity with Government policy, the country's development partners are also preoccupied with farm output increasing measures. FAO assistance in Sierra Leone, for example, focuses on three priority areas namely, i) support to smallholder farmers to increase farm productivity; ii) assisting government in the process to modernize its land tenure system; and iii) put in place enabling policies to encourage investments in agriculture, thereby alleviating food insecurity. ${ }^{1}$ Similarly, USAID, in addition to supporting activities to improve food availability and access, supports integrated agriculture-aquaculture systems and rice value chain programmes in a bid to promote private sector investment in agriculture. $^{2}$

The discussion has amply demonstrated that several socio-cultural factors contribute to food insecurity in the country. It is concluded, therefore, that 'agricultural' factors alone are inadequate to account for the persistent annual occurrence of seasonal hunger. A comprehensive explanation must take due cognizance of socio-cultural factors such as the over-dependence of the majority of the population on rice as their main staple; the excessive use of food for participation in religious and traditional festivities; and poor household management of available food resources.

As a complement to the conventional measures to promote food security, therefore, the effect of these sociocultural issues on household food security need to be taken into account and appropriate extension messages for farmers developed and incorporated in the training programmes of agricultural extension personnel, if Government's priority goal of national food security is to be realized.

\section{References}

Arai, T., Aiyama, Y., Sugi, M. \& Ota, J. (2001), "Holonic Assembly System with Plug and Produce",

Hart, W. (2006). Government of Sierra Leone, in collaboration with WFP, UNDP, UNICEF, WHO and FAO: Report of the Vulnerability Analysis and Mapping, WFP Sierra Leone. (March 2006).

Johnny, M. (1979). Traditional farmers' perceptions of farming and farming problems in the Moyamba area. Department of Geography, Fourah Bay College, University of Sierra Leone.

Johnny, M. (1981). Agricultural Change and Peasant Farmer Resistance: The Case of the Traditional Upland Rice Farmer in Sierra Leone. Rural Africana, 10, 9-17.

Johnny, M., Karimu, J., \& Richards, P. (1981). Upland and swamp rice farming systems in Sierra Leone: the social context of technological change. Africa, 51(2), 596-620.

Richards, P. (1986). Coping with hunger. Hazard and experiment in an African rice-farming system: Allen \& Unwin.

\footnotetext{
${ }^{1}$ www.fao.org $>$ country profiles, Sierra Leone

${ }^{2}$ USAID; https://reliefweb.int>report, Sierra Leone Food Assistance Fact Sheet, January 2018.
} 